Revista de la red interuniversitaria de estudios sobre las literaturas rioplatenses contemporáneas en Francia

$18 \mid 2018$

El río y la ciudad

\title{
Alfredo Veiravé y sus paisajes laterales
}

\section{Claudia Rosa}

\section{OpenEdition}

\section{Journals}

Edición electrónica

URL: http://journals.openedition.org/lirico/5621

DOI: 10.4000/lirico.5621

ISSN: 2262-8339

Editor

Réseau interuniversitaire d'étude des littératures contemporaines du Río de la Plata

Referencia electrónica

Claudia Rosa, "Alfredo Veiravé y sus paisajes laterales », Cuadernos LIRICO [En línea], 18 | 2018,

Puesto en línea el 10 octubre 2018, consultado el 19 abril 2019. URL : http://journals.openedition.org/ lirico/5621 ; DOI : 10.4000/lirico.5621

Este documento fue generado automáticamente el 19 abril 2019.

\section{(c) $(1) \Theta \Theta$}

Cuadernos LIRICO está distribuido bajo una Licencia Creative Commons Atribución-NoComercialSinDerivar 4.0 Internacional. 


\title{
Alfredo Veiravé y sus paisajes laterales
}

\author{
Claudia Rosa
}

1 El mal que aqueja a la literatura argentina no es la extensión sino la apropiación de la cultura de la pampa húmeda, que alcanza la forma de lo nacional por sobre las producciones literarias de otras regiones del país. Un hiperprovincialismo expandido con pretensiones cosmopolitas. $\mathrm{Y}$ en estas constelaciones creadas a las sombras terribles del siglo XIX, que no terminamos nunca de invocar, aparece como contrapartida la impronta litoraleña que todos nosotros estamos empujados a evocar. En el meollo de nuestra voluntad siempre está el paisaje más o menos ficcionado, más o menos justificado. Quiero decir que todos sabemos de la ausencia, en variables relativamente estables, de una representación literaria del río y de las ciudades y pueblos litoraleños como forma, y proponemos en cambio un nuevo sistema de texto en el que los referentes geográficos se hacen explícitos.

2 El texto que aquí presentamos integrará la colección El País del Sauce de la Editorial de la Universidad de Entre Ríos (Eduner) que "toma como motivo la región que trazan los valles de los ríos Paraná y Uruguay pero que tienta un espacio más bien impreciso, menos geográfico que imaginario, delimitado por aquellas voces y miradas que participan de su formación". Como toda trama, este país del sauce es un espacio de tensiones más o menos estables en donde se da una serie de órdenes jerárquicos, de organizaciones internas y externas, en donde pretenden justificarse y hasta hipertextualizarse numerosas $\mathrm{y}$ disímiles obras literarias. Construimos una tradición de una literatura natal y pensamos en un sistema escrito desde una skené nativa que teatraliza ante el mundo, a la manera del teatro griego, subido sobre sus coturnos y cuya acústica permite que aun el leve suspiro juaneliano sea escuchado en diferentes lenguas; un foro natal desde el que se habla al mundo entre dos ríos. Esta es una de las zonas de la literatura argentina, quizá la primera que se separa de la zona pampeana, y se construye sobre padres fundadores como José Hernández, al que los entrerrianos llamábamos "Matraca" porque hablaba fuerte y mucho y que pasó años escribiendo en estas, nuestras calles y colinas, la gauchesca. Pero esta tradición natal tiene también sus herederos, ahora en trance de devorar al padre, en una 
tramitación necesaria para construirse, como sucede con la zona saeriana de la provincia de Santa Fe.

“Detrás de los libros argentinos que se tienen por 'representativos' o documentales se esconde esta reflexión de sus autores: puesto que somos pobres de historia y de tradiciones, conviene magnificar las potencias de la tierra, el espacio natal"'. Así explicaba Mastronardi la propensión al duelo criollo entre nacionales y regionales, entre localistas y universalistas, entre comarcanos y cosmopolitas. Somos pobres en tradición literaria, si consideramos que Lugones sería formalmente nuestro primer gran hombre de letras en términos modernos y de esto hace poco más de 100 años.

Con una prosapia contextualista, el mismo impulso de búsqueda de la identidad de un grupo, y con la misma debilidad teórica que otros conceptos englobantes, la noción de país del sauce vino para quedarse.

5 Y si vamos a persistir en construir una zona llamada país del sauce tendremos que realizar diferentes operaciones que incluyan otras tensiones estéticas y cuyas angustias de la influencias vayan más allá de los juaneles, los saeres o los madariagas. No porque estos no alcanzasen para fundar una nación poético-lingüística sino porque para construir un país se necesita tanto de padres fundadores como de revolucionarios, de miembros del establishment como, por supuesto, de una bohemia cultural, evitando así el anquilosamiento de toda paternidad.

6 He aquí una hipótesis que traigo a discusión. La operatoria de Veiravé, que podríamos en algún punto compaginar con la lógica de la santafecina Amelia Biagioni, crea primero un itinerario retórico-espacial de latinoamericanización de la zona para otorgarle luego un carácter tecnológico trasnacional. Alfredo Veiravé, en el momento del distanciamiento de la terrible influencia juaneliana, y camino a la construcción de su propia esfera poética, procura un tránsito que va de la melancólica ciudad de Gualeguay -el río ausente- a una hispanoamericanización de un Chaco casi innombrado hacia 1970 y redobla la apuesta de Francisco Madariaga para dejar de ser un criollo universal y ser un litoraleño interestelar.

\section{Proyecto creador. Gualeguay, primer paisaje}

7 El primer camino es el que ya ha marcado la crítica. En sus primeros libros el poeta estaba bajo la esfera de la poesía de Juan L. Ortiz y su pregnancia de Gualeguay, y luego, ya en los 70, encuentra en el Chaco un territorio más cerca de Latinoamérica. Como bien explicó Madariaga, América Latina comienza en Corrientes, así que el salto de Gualeguay a la patria grande era natural casi.

8 A Veiravé le cuesta tres libros y una década superar la angustia de esa influencia juaneliana, y otra década más, con tres libros más, lanzarse hacia las fertilidades de un nuevo territorio expandido. Se desplaza dos veces: una de las retóricas simbolistas francesas y otra de las hispanoamericanistas.

9 Según Elisa Calabrese ${ }^{2}$ la instancia de la construcción autoral sucede en los 60 y se da entre el género poético y el crítico, lo que se observa, por ejemplo, en la predilección manifiesta en sus textos por la enseñanza de la literatura latinoamericana, por ahondar en ciertos momentos de la cultura de nuestro subcontinente; alguno de estos temas aparecen también en clave poética en El imperio milenario, poemario de 1973. 
10 Encasillado como perteneciente al neorromanticismo del 40 y coetáneo del surrealismo, del invencionismo y la antipoesía, Veiravé se para en las antípodas del objetivismo, el nacionalismo y la poesía social comprometida. Él sabe que para encontrar voz propia debe alejarse del ruido y junto con su amiga Amelia Biagioni hacen de su estancia provincial un lugar de contención contra las tendencias poéticas dominantes de su época en favor del desarrollo de una poesía que, atendiendo especialmente a la polisemia del término, podríamos calificar como alternativa, tanto por su corrimiento de los ejes establecidos como por su condición cambiante y nómade, la cual determina su singularidad y originalidad. Si bien Veiravé se caracterizó por su bajo perfil, consecuente con una notoria preferencia por el alejamiento de los círculos literarios de prestigio, su gesto grandilocuente se encuentra, sin lugar a dudas, en su poesía.

11 La trayectoria del poeta, que abarca más de cuatro décadas de intenso trabajo, evidencia a simple vista una cuestión para nada menor: su poética, que en principio se adecua a ciertas convenciones genéricas y normas propias de lírica clásica, alcanza su punto álgido a partir de la transgresión de dichas normas, de la puesta en cuestión de los principios de la tradición y de los códigos vigentes en su tiempo. En este sentido, Veiravé, como Biagioni, se presenta como un autor que legitima su obra:

[...] se arma al margen de los mandatos del establishment e independientemente de las poéticas dominantes en la Argentina de la segunda mitad del siglo XX. [...] se despliega rompiendo con su propio origen y se cumple de una manera originalísima, habiendo recurrido a tradiciones tan diversas como el neorromanticismo cuarentista, la vanguardia girondiana, el romanticismo alemán y la poesía pura tal como la concibiera Mallarmé ${ }^{3}$.

Pero al mismo tiempo, la transformación se gesta en el seno de su propia labor poética: sus poemarios, lejos de seguir una trayectoria lineal, experimentan una transformación radical que se materializa con mayor fuerza en sus últimos libros. Su producción primera había tendido a la autorreferencialidad del yo poético y estaba volcada al verso en rima y al uso de los metros tradicionales, y es sólo en este período inicial que Veiravé habla del río. Estos poemarios se caracterizan por su acentuada influencia neorromántica, reforzada por una instancia subjetiva y autorreferencial, un yo lírico de corte autobiográfico que se relaciona estrechamente con la subjetividad de la poesía, dando lugar a una profunda exploración autorreflexiva de progresión emocional que se sostiene en un lenguaje altamente metafórico, vinculado particularmente con lo que transmiten los ojos y la mirada. Los versos se configuran como pasajes poéticos en los que se plasman y condensan imágenes cargadas de lirismo. Estamos hablando de sus tres primeros libros, aquellos que fueron prácticamente editados y corregidos en la casa misma de Juan L. Nos referimos puntualmente a El alba. El río y tu presencia (1951); Después del alba, el ángel (1955) y El ángel y las redes (1960). Un amplio conjunto de rasgos temáticos ubican esta primera etapa de la poesía de Veiravé en un terreno en el que el yo aparece como eje ordenador del poema, al tiempo que la subjetividad invade el discurso poético.

Pero la vida en el Chaco, donde se radica en 1957, trajo consigo una profunda transformación en su escritura. Veiravé comenzó en esos años una innovación del proyecto creador: nuevas camaraderías, nuevas lecturas, nuevos tiempos políticos. 


\section{El Chaco intergaláctico}

14 conectada a América Latina que la propia Entre Ríos, y es allí donde conoce la noción de cofradía de artistas. Sucede que en los 60 en Resistencia el poeta está muy cerca de Santiago del Estero, donde tenía lugar la fuerte actividad de Francisco René Santucho, quien trabaja junto con Kusch en la elaboración de la noción de la América Profunda, y que desplegará un centro indigenista antropológico en Santiago del Estero desde 1957 hasta su entrada en el movimiento armado en 1967. Resistencia está también cerca de Buenos Aires, que en la capital chaqueña no es denostada como lo hacían los entrerrianos. Allí, en Resistencia, en la Casa de Gobierno del Chaco, Emilio Pettoruti hace un enorme mural de seis por tres metros. Allí se desarrolla una cofradía que sostiene un espacio como el Fogón de los Arrieros. Por ese espacio pasaron Borges, Elisa Stram, Yehudi Menuhin o el mimo Marcel Marceau. El lugar tiene a un costado un "cuarto de maravillas" o "gabinete de curiosidades", igual nombre que se daba a los sitios en los que en los siglos XVI y XVII se exponían los objetos novedosos y exóticos que resultaban de los viajes de exploración a tierras lejanas. En ese espacio conviven, entre otras cosas, un guante de Monzón con una partitura de Atahualpa Yupanqui o un corpiño de Marlene Dietrich. La imagen de este cuarto de las curiosidades nos sienta mejor para tratar de narrar este desplazamiento del espacio nativo, esta operatoria de Veiravé para ubicar a Chaco en una zona interestelar: el espacio infinito de la esfera celeste y de la técnica que conlleva describirlo. Allí Veiravé entiende que la literatura no es un trabajo en soledad como pareciera. Allí está lleno de pares que acompañan, contienen y contagian: Hermes Villordo, María Elena Walsh, Amelia Biagioni, Emilio Soto, Sara Facio, Carlos Alonso, Rafael Oterio, Córdova Iturburu, Roberto Ledesma; una cofradía de artistas que debieron repensarse para poder sostener su proyecto creador por fuera de los grupos que dominaban la cultura nacional.

En este contexto, entre 1956 y 1962, se publica en Santiago del Estero la revista Dimensión. Esta publicación, dirigida por Santucho y que recibía las colaboraciones de intelectuales y artistas de diferentes provincias de la región, incluso de intelectuales de otros países latinoamericanos, se caracterizó por ejercer desde sus páginas el regionalismo cultural. Son estos miembros y colaboradores quienes crearán, poco antes de que la revista dejara de publicarse, el Frente Revolucionario Indoamericano y Popular (FRIP), el mismo que fusionado luego con la agrupación de orientación trotskista Palabra Obrera da origen al Partido Revolucionario de los Trabajadores (PRT). El indoamericanismo profesado por Santucho se había ya manifestado a través de un artículo que publicara en la revista Oral organizada por la SADE. La nota se titulaba "El drama de América" y en ella expresa la problemática que sería de algún modo el horizonte de la revista Dimensión y el fundamento de todas las actividades culturales que desde la revista se organizaran. La participación de Orestes di Lullo, Bernardo Canal Feijóo, Horacio Rava y Alfredo Gargano, así como la intervención de personalidades de otras provincias como Atahualpa Yupanqui, Lázaro Flury, o la incursión del premio Nobel Miguel Ángel Asturias, por mencionar algunos nombres, evidencian que, sin importar las diferencias generacionales o geográficas, se establece y se articula un diálogo gracias a la revista y a través de ella. Las temáticas diversas que los escritores despliegan en sus colaboraciones generan la 
puesta en discusión de la problemática latinoamericana. Al respecto, se pregunta César Gómez:

¿Qué supone ese acto de pensar y hacer, esa incitación de orden vital en un contexto periférico como el de Santiago del Estero entre los años 50 y 60? [...] A la luz de sus promotores, la revista era una herramienta de expresión necesaria, y entre las circunstancias que la volvían imprescindible estaba la pertenencia a un regionalismo que no encontraba definición en el escenario nacional: un regionalismo con fuertes notas peculiares, representativas de un estado esencial de profundas diferenciaciones ${ }^{4}$.

Junto con los 60 vino la antipoesía y el coloquialismo, para plantearlo en términos de Fernández Retamar ${ }^{5}$, pero también vinieron las invenciones en torno a El llano en llamas (1953) o Pedro Páramo (1955) de Juan Rulfo o de una novela como Zama de Antonio Di Benedetto, por citar algunas obras recurrentes en las clases veiravianas.

Sin embargo Veiravé huye de la angustia localista y da el zarpazo a través del humor y de un supuesto absurdo. Algunos críticos han visto en él la imagen surrealista; preferimos detenernos en su tono. Los 60 fueron antisolemnes y profanos y la seriedad era algo que no le cabía a Veiravé o, en otro registro, era el humor lo que lo unía a Juan L. Ortiz. Y es justamente el tono reflejado en su registro, lo que lo separa de Juan L. Y su no formación marxista. Es que la izquierda andaba siempre pletórica de buenas intenciones y buenas ideas, y el origen de la sátira no es la reflexión sino el prejuicio. De ahí que su ironía haya florecido en un ambiente como el Fogón de los Arrieros. Veiravé se aleja de esa centrípeta fuerza de los 60 dominada por la disputa entre bohemios y burgueses. Él no estetiza la bohemia, ni la teatraliza, ni satiriza la burguesía. Veiravé, como sus amigos Hermes Villordo o Amelia Biagioni, entendieron rápido que la bohemia es sólo una manifestación social del espíritu romántico y huyeron de ella al compás de su alejamiento del neorromanticismo de los 40 . Entonces los poemas se dilatan. No sólo se hacen más largos sino que se expanden en tiempos y espacio y las series temáticas estallan.

Veiravé publica en 1980 Historia natural, un libro que, como veremos más adelante, es una parodia, un homenaje y una antimonumentalidad a un nuevo barrio de esta provincia llamada El País del Sauce.

\section{El dualismo de los 60}

19 La década del 60 trajo una nueva forma de política, de cultura, de arte, pero también asociaciones $\mathrm{u}$ oposiciones irreconciliables: Kennedy y las relaciones peligrosas / Sexo, drogas \& rock n'roll / El Che y el Tercer Mundo / Brigitte Bardot o la Nueva Mujer / Onganía y la violencia engendra violencia / El Di Tella y otras movidas / Los medios o la nueva política / Intelectuales que se debaten entre el compromiso y la fama / Jóvenes iracundos y artistas que producen consumos masivos ${ }^{6}$. $\mathrm{El} \mathrm{hecho} \mathrm{es,} \mathrm{paradójicamente,} \mathrm{que}$ estos dualismos han permitido la proliferación de híbridos que violan sus principios.

Cabe aquí preguntarnos con Latour?: ¿qué es lo que permite que este híbrido dualismo proliferante emerja en Occidente? Su respuesta a la pregunta sobre la "Gran División" es que nosotros en Occidente somos la única cultura que moviliza la naturaleza. Movilizamos la naturaleza, no como signo, sino tal y como es, y lo hacemos mediante la ciencia. Así Claude Lévi-Strauss escribe que el pensamiento salvaje accede al mundo físico por el desvío de la comunicación, mientras que Occidente llega al mundo de la comunicación por el desvío de la física ${ }^{8}$. 
21 El poema es para Veiravé enunciación, es decir, siempre y al mismo tiempo, comunicación de su mismo verso. No es nunca representación pura. o hecho puro. En sus efectos se asemeja más a un acto de habla que a una mera expresión predicativa. Es la parole entendida no como habla sino como mensaje: siempre incluye su envío. Y el envío teje una red, ayuda a construir un sistema. Aquí, los cuasi-objetos se encuentran entre los más importantes de estos "mediadores". La propia mediación, por supuesto, significa mucho más que mera representación. La representación implica el tipo de prácticas que tienen lugar en la escultura, la pintura, la novela, el poema.

Un orden de rastreo no tiene tanto que ver con la representación de una narrativa lineal o incluso ni siquiera con la problematización de la representación mediante la narrativa no lineal. Tiene que ver en cambio con la irrelevancia de la representación: la irrelevancia de la narrativa. Tiene que ver con lo que Lefebvre ${ }^{9}$ llama un "sendero", un sendero material, un sendero indicial y táctil que rastreamos y que después abandonamos y con el que volvemos a conectar. Quizá sea ésta la forma en que producimos sentido y significado en la cultura contemporánea.

\section{El paisaje lateral en Historia natural}

Si bien la conexión entre los poemarios es manifiesta, y ciertas continuidades que funcionan a modo de ejes estructurales son, a su vez, innegables, la escritura de Veiravé comienza a evidenciar notorias modificaciones a partir de su cuarto libro, Destrucciones y un jardín de la memoria, de 1965. La rima deja de ser un elemento fundamental para aparecer esporádicamente; las enumeraciones asindéticas comienzan a poblar los poemas, y los encadenamientos sintagmáticos pasan a prescindir de las reglas gramaticales y lingüísticas convencionales, generando efectos vinculados con el orden de lo rítmico y lo sonoro. Asimismo, las estrofas, entendidas como unidades métricas de sentido, dejan paso a la libre disposición de los versos en la hoja, y la distribución de las palabras en la página se resignifica a partir de la utilización productiva de los espacios en blanco. La lógica racional que sobrevolaba los primeros poemarios tambalea frente a una explosión polisémica que se dispara hacia múltiples direcciones, obturando la comprensión unívoca del discurso poético y favoreciendo una diseminación que parece sostenerse en los contrastes de palabras, el puro ritmo, la cadencia acumulativa y la expansión de cadenas de versos ad infinitum.

24 A partir de este momento se distinguen en su obra poética y específicamente en Historia natural (1980) dos modulaciones principales de su atlas universal: por un lado, una modulación totalizante, y otra hacia lo pequeño, lo casual, lo anecdótico. Sus cuasi autorretratos porfiadamente buscan precisar o definir la imagen del yo en el cosmos, la relación entre lo cotidiano, los sucesos y eventos inmediatos, y aquellos de tiempo largo, históricos.

En su discurso de recepción del Premio Iberoamericano de Literatura Pablo Neruda (2004), José Emilio Pacheco explicó: “Sin ponernos de acuerdo, en las ciudades hispanoamericanas quienes en los sesenta tuvimos de 20 años a 30 años aspiramos a otra poesía y a una actitud distinta, más próxima al transeúnte de las calles citadinas que al bardo y al chamán"10. Aunque se le llame neovanguardia, no hay entre los poetas de estas distintas ciudades un manifiesto común sino una necesidad estética y ética de involucrarse con su tiempo. De entrada es eso: una actitud diferente que se manifiesta en 
la relación del poeta con las demás personas, con el lenguaje y con la retórica establecida. El poeta es ahora un hombre común entre otros hombres comunes.

En la conferencia "La música en la poesía", dictada en la Universidad de Glasgow en 1942, Eliot asentó:

Pero existe una ley de la naturaleza más poderosa que cualquiera de estas corrientes, o influencias del extranjero o el pasado: la ley de que la poesía no debe alejarse demasiado del idioma ordinario que usamos y oímos cotidianamente. Sea acentual o silábica, rimada o no, formal o libre, la poesía no puede permitirse perder contacto con el cambiante lenguaje del intercambio corriente ${ }^{11}$.

Veiravé arremete con una sutil sátira a los saberes consagrados en donde el solo hecho de expandir el espacio chaqueño a dimensiones interestelares o históricas hace estallar las viejas series temáticas. En Historia natural, cuando él intenta fundar un nuevo territorio, comienza justamente con Plinio y con un epígrafe de Malraux: además de hablar de que las civilizaciones se sepultan y se reviven en un Museo Imaginario también lo hacen en el acarreo del nombre "Malraux". En cierto modo vuelve a plantar las estatuas que el propio Malraux robaba en Camboya cortándoles los pies para traerlas a Francia.

Esta Historia natural contiene un museo de ciencias naturales imposible en donde se amontonan el Zamuhu o palo borracho; Hyeronymus Bosch, que se asusta de pintar ese bestiario de símbolos carnales que es Resistencia; Nicolás Copérnico, que se sumerge en una piscina mientras se disuelve en la poesía; los premios Nobel de química, intentan explicar el paso del Río Negro que atraviesa la capital de Chaco, por citar sólo algunas transformaciones.

Historia natural es desmesurada. Es una recolección absurda, sin embargo, y cada objeto coleccionado está tratando de ejercer presión dilatando el espacio y el objeto local. La angustia ante el cruce de un río, por ejemplo, se transforma en complejas explicaciones físico-químicas que expanden el objeto, el espacio y el tiempo. Esta dilatación es muy diferente de la disolución juaneliana.

Hay un goce en esa dilatación que se expande hasta adquirir conciencia cósmica. Es un trabajo libidinal opuesto al de Ortiz, en donde la retención sacrifica el presente en una constante martirización para alcanzar la obra. Veiravé, hombre de su época, supera la esquizofrenia del burgués o bohemio que, como lo señala Daniel Bell en 1976, en Las contradicciones culturales del capitalismo ${ }^{12}$, habría llegado a un raro punto de equilibrio inestable.

31 Se suele hablar de sus enumeraciones. Pero la enumeración no se ejecuta sólo eso en este libro. Hay, para ser más exactos, una serie de implosiones: las arañas y los trasatlánticos, Robert Lowell y el Bosco, los turistas y una ballena en el Chaco, un sapo de Li Po en un laboratorio de pruebas de embarazo, la lluvia y los pájaros de EE.UU. y de Resistencia, cangrejos en las playas de Brasil y un cuadro de Botticelli. Pero las series semánticas no sólo implosionan los campos semánticos sino que construyen otros paisajes laterales.

Las series lexicográficas, las series sígnicas, piedras nodales del estructuralismo, no son sino en mayor grado el refinamiento de lo que había comenzado con la modernidad: la necesidad de aclarar, ordenar, clasificar, acumular. "Quizás la postmodernidad, la conciencia postmoderna, consista sólo en la teorización de su propia condición de posibilidad que es ante todo una mera enumeración de cambios y modificaciones"13.

33 Pero pareciera que Veiravé hace implosionar el campo de las series de las cosas, de los nombres y de los paisajes; esto es: propone una ruptura hacia dentro mismo del sistema 
poético que lo sostiene, debido a que las estructuras poéticas, las visiones, las series construidas y ya institucionalizadas en la poesía litoraleña, debían quebrarse. El concepto de implosión lo tomamos de Baudrillard en tanto que la representación de lo real ha implosionado debido a que la representación misma es una modificación o simulación de lo real que pasa a constituirse en hiperreal. Baudrillard dirá que hoy en día:

[...] la abstracción ya no es la del mapa, la del doble, la del espejo o la del concepto. La simulación no corresponde a un territorio, a una referencia, a una sustancia, sino que es la generación por los modelos de algo real sin origen ni realidad: lo hiperreal. El territorio ya no precede al mapa ni le sobrevive. En adelante será el mapa el que preceda al territorio -precesión de los simulacros- y el que lo engendre, y si fuera preciso retomar la fábula de Borges, en que los cartógrafos del imperio trazan un mapa tan detallado del territorio que llegó a recubrir con toda exactitud al mismo que, con el tiempo y debido a su inutilidad, es finalmente abandonado. Hoy serían los jirones del territorio los que se pudrirían lentamente sobre la superficie del mapa, son los vestigios de lo real, no los del mapa, los que todavía subsisten esparcidos por unos desiertos que ya no son los del imperio, sino nuestro desierto. El propio desierto de lo real ${ }^{14}$.

Se ha confundido la separación tajante entre lo real y su representación en la medida en que territorio y mapa se han acoplado hasta invertir su relación y es el mapa el que precede al territorio, con lo cual lo real se presenta, como un exceso no verificable, en lo hiperreal. Los paisajes de Veiravé no son de acá ni de allá, de ayer ni de mañana, son el momento de la serie implosionando, moviéndose, comiéndose el sema. Las nociones que establecían un mundo representable y diferenciado han implosionado por efecto de acoplamiento de lo real que sale al encuentro en la intención de "capturarlo" en conceptos como poeta u objeto poético. En la física, la implosión es la ruptura hacia dentro de un sistema. Por semejanza, Baudrillard llama implosión al rompimiento interior que se origina cuando se desinfla de significados el mundo.

Alfredo Veiravé en El imperio milenario de 1973 había abierto la puerta de manera definitiva a una comprensión diferente de su concepción poética y de su escritura. El título del poemario prefigura una dinámica de fuga y persecución, de intercambios e inversiones de roles y de tradiciones. Es, digamos, de una manera simple, una fuerte domiciliación de la zona en Latinoamérica junto con la que realiza Madariaga ese mismo año con Tembladerales de or ${ }^{15}$. En Historia natural de 1980 se redobla la apuesta. La concatenación y acumulación de términos, mediante el despliegue de estructuras sintácticas cuya recursividad podría ser considerada como redundante bajo los parámetros de una "lógica del habla", en este caso suscita una multiplicidad de sentidos simultáneos.

36 También resulta significativa la distribución irregular de los espacios gráficos y de los blancos de la hoja: el desplazamiento hacia la derecha de los versos sueltos y de sintagmas oracionales que aparecen como interpolaciones de otra voz en el poema. En este sentido son reiteradas, por ejemplo, las referencias a una serie de tópicos e ideas acerca de la ciencia, del arte y su puesta en práctica, de la producción pictórica per se y el rol del artista. En términos generales, las disquisiciones sobre la potencia y la capacidad científica de explicar el acto creativo y las dificultades que este conlleva son cuestiones que, extraídas de los fragmentos, se interpolan con insistencia en los poemas. De esta manera, como un museo dislocado, el poemario combina la escritura con elementos pertenecientes al orden de la ciencia; tanto el orden de lo musical propio de una partitura, como al movimiento del pincel en un lienzo. Así el poemario logra configurarse como espacio de multiplicidades en el que confluyen elementos y procedimientos 
vinculados a la ciencia pictórica -o musical o literaria-, conjugando órdenes cognitivos divergentes que interactúan y que muestran su imposibilidad de dialogar entre sí. En esta Historia natural el espacio euclidiano se curva por efecto de la dilatación, como si el calor chaqueño dilatara los objetos que explican el comportamiento musical de los espacios infinitos. Justamente un poema titulado "Una gran constelación nos atrae" dice:

Lamentablemente vamos hacia un agujero cósmico. Felizmente vamos

Envueltos en la música de los astros

Al compás del violín de Yehudi Menuhin que escuchamos en Londres

Porque a mí también,

El silencio de los espacios infinitos me aterra ${ }^{16}$.

Dos puntos. Yehudi Menuhin había actuado en Resistencia y "el silencio de los espacios infinitos" remite a las conversaciones con Juan L. Ortiz, dos interlocutores que se encontraban a mano. El violín y el poema infinito son destemplados o llevados a otra escala.

Parafraseando a Sloterdijk, podríamos decir que no es cierto que el inicio de la poesía sea la sorpresa sino la competencia entre poetas. Antes es la necesidad de abrirse caminos en la selva espesa de las retóricas epocales que el descubrimiento de un nuevo mundo de objetos. Intentemos ahora describir cómo creemos que eso funciona en este poeta.

\section{Un infinito minúsculo}

Alfredo Veiravé apunta a que la mejor manera de percibir el infinito es lo minúsculo cercano en tensión con lo ultra macro, con lo intergaláctico. El mismo Veiravé lo explica así en un texto de 1960:

Empiezan allí con evidencias las notas de un "universalismo" que yo había visto claro cuando vine al Chaco y debí ver de cerca la poesía "telúrica" (hacheros y algodonales se repetían en esta nueva provincia, aquellas "lanzas" y "golillas" de los montieleros poetas entrerrianos que no habían advertido el cambio que operaba en el siglo XX), es decir, sobre los hacheros chaqueños pasan hoy satélites artificiales. Esto, que lo repetí muchas veces hace 10 años, puede ampliarse diciendo que hoy [1969] podemos estar en un pueblo del interior del Chaco que se llama Villa Ángela y al cual me siento muy unido, y escuchar la voz de los astronautas posados en la luna. Los medios de comunicación, de información y de divulgación han hecho de cada región un reflejo del mundo universal; no entender esto es fatal. Además, yo estoy convencido de que ese prejuicio muy español de ser regional para ser universal es un cuento chino en 1970. Octavio Paz, en sus brillantísimos ensayos sobre una literatura de fundación (creo), ha dado en el clavo cuando señala la importancia de Darío como fundador de una Modernidad que no ha concluido, es claro. Los modernistas, dice, sintieron que Francia o Europa mejor dicho (con exclusión de España) pertenecían a un siglo nuevo, y viajar a París era un deseo de estar en el siglo XX. Sí, es cierto, pero ahora se puede vivir también en Resistencia y estar en el siglo XX siempre que uno se saque de encima los prejuicios del telurismo (Julio 1970) ${ }^{17}$.

40 Historia natural nos importa porque presenta por primera vez una voluntad explícita de construir una propia enciclopedia y porque no puede evitar esbozar una suerte de filosofía, donde la propedéutica de la intimidad se convierte en materia extensa, como una gran mancha libidinal que todo lo toca, una panlibido a partir de la cual pueda leerse este libro de los excesos. La empresa podría llamarse ahora, en etapas sinópticas: el redondeamiento de lo exterior. Aquí, la hipérbole no sólo se documenta como un medio estilístico sino como un procedimiento para construir nuevos contextos. Esta Historia 
natural hiperbólica corresponde al primer proyecto en tanto tal, en el que se habla de la constitución íntima de la díada entre lo cercano y lo intergaláctico. A la salida de la situación fundamental familiar -y su símbolo arquitectónico, la casa-, el programa expansivo pasa del pueblo a la ciudad, al imperio y, más allá, al universo, perdiéndose en un espacio ilimitado e inhabitable.

41 Alfredo Veiravé, siguiendo la genealogía de la zona Ortiz, Madariaga y Calveyra, ha cultivado, en el más alto grado, el sentimiento cómico de la vida, pero no como opuesto al sentimiento trágico, sino como una variante que lo agrava al purificarlo del superfluo patetismo de la seriedad. El humor es una constante en su escritura si uno se atiene a leer como juego los saltos de sus esferas poéticas. No es mero chiste, sino, en sentido más estricto, humor lexicográfico. Así ingresan a la poesía de la zona, la región hispanoamericana, los aportes de la tradición anglosajona y una preocupación sociológica, histórica y antropológica que atraviesa el discurso poético en busca de nuevos mecanismos de representación de lo real.

Por otra parte, Veiravé tuvo que vérselas de cerca con el vitalismo de los 60. Esa es otra frontera que delimita su poética. El movimiento resitúa en el contexto latinoamericano algunos de los principios fundamentales de las vanguardias históricas: voluntad de ruptura, vinculación entre poesía y política, recuperación del proyecto arte-vida, actitud iconoclasta, experimentalismo textual. Su singularidad latinoamericana es evidente, tanto en sus manifiestos como en sus textos, y obedece, más allá de su voluntad de romper con la tradición poética, a una corriente que alimenta la búsqueda de una expresión de raigambre marxista en el contexto posrevolución cubana, incorporando la dimensión popular y marginal de la cultura. Se trata de un realismo de vanguardia que articula un discurso de alta complejidad cultural con los lenguajes marginales; sólo así puede comprenderse la integración de diversos géneros y disciplinas en un macrotexto complejo y fuertemente experimental. Esta es otra de las fronteras de Historia natural. Si tenía el infinito esencialista juaneliano por una frontera y el criollo universal por otra, debía cuidarse bien de no quedar atrapado en los muros del vitalismo post-Residencia en la Tierra.

Entonces se podría pensar a partir de Sloterdijk ${ }^{18}$ que Veiravé opta por esta salida intergaláctica que hace detonar incontables esferas pequeñas, que ocasionalmente se recomponen en formatos mayores. Lo minúsculo se desvanece en lo macro. Una vez más: la microsfera es un lugar en donde se instala un sentido y a través de las series se va manteniendo una semiosis que tensa hacia lo macro: lo intergaláctico. Estas isotopías son hibridas, elásticas, se expanden y, para decirlo en términos del filósofo alemán, en su contacto con la geometría el alma va inflándose hasta la esfera-todo. De ahí la creencia exaltada que tiene esta Historia natural en la naturaleza del espíritu humano para conseguir una especie de conocimiento cómplice de las primeras y últimas cosas; de ahí también la suposición inicial de los principiantes del ser, fácilmente defraudable, de poder llevarlo a gran escala en la tierra. "Todo yo era cabeza; y era redondo como un círculo, como se representa la perfección y la eternidad; esto me permitió hacer planes para el futuro... me dispuse a la conquista del mundo..." ${ }^{19}$.

Esta Historia natural presupone varias co-vidas con desarrollo multifocal y multiperspectivista. Su punto de partida reside en una definición no-metafísica y noholística de la vida: su inmunización ya no puede pensarse con los medios de la simplificación ontológica. No existe la región pequeña porque lo que es "la vida" actúa ilimitadamente, conformando espacios de diversas maneras, no es sólo porque cada una 
de las mónadas tenga su propio entorno, sino más bien porque todas están ensambladas con otras vidas y se componen de innumerables unidades. La vida se articula en escenarios simultáneos, imbricados unos en otros, y se produce y consume en talleres interconectados.

Historia natural, con esta nueva concepción de los espacios y los tiempos, se refuerza con su otra obra, Radar en la tormenta, el libro que le sigue, del 85. Radar ya es una potente imagen de "cazador de palabras al vuelo".

Aquí la apuesta se redobla. "Cubrir" o "rastrear" suenan más como el trabajo de un detective que como el trabajo de un juez o de un colector museístico. Y quizá es eso lo que preocupa en la cultura global informacional. Los modernos ya no somos quizá "jueces" sino "rastreadores". Nos conciernen menos las representaciones que el envío, la señal. Ya no somos premodernos de lo simbólico, ni icónicos como los modernos, sino que nos hemos mudado a un orden indicial de no representación. La poesía es la parábola que señala el objeto. Así no sólo los científicos sociales, sino todos nosotros, los lectores, devenimos rastreadores de objetos. En todos esos casos, no se trata tanto de la representación o de lo simbólico, sino de información y envío. No hay ni auralidad juaneliana (lo simbólico), ni visión (lo icónico) calveyriano, sino tactilidad e indicialidad en el corazón de la economía de los signos y de la información.

\section{Modus operandi de la selva seca intergaláctica}

Uno estaría inclinado a pensar que, en la poesía de Historia natural, no parece que los objetos hayan sido causados por los sujetos, sino que más bien son portadores de ciertas propiedades que los sujetos poseen. Para Veiravé, por lo tanto, los objetos tienen agencia: no una agencia causal como en el naturalismo. Tienen, más bien, derechos, responsabilidades; pueden juzgar y valorar, pueden mediar. Exactamente igual que los sujetos. Así, los objetos de Historia natural no están causados en primer término por sujetos. Al contrario, son semejantes a los sujetos. Los objetos de esta Historia natural no son construidos por el poeta a la manera del maestro Juan L. sino que pareciera que ellos mismos se construyen por "mediación" y "delegación". Y que los poetas son meros traductores. Son estos objetos los que hacen sonar el radar para expandir la zona nuevamente llamada país del sauce.

La estilística resultó ser una especie de materialismo cultural ${ }^{20}$ en donde la materialidad es de la lengua y de las convenciones literarias bajo la ingenua estrategia de un supuesto análisis de estilo. Podríamos considerar como una zona de este país del sauce a una historiografía literaria que se caracteriza por proveer una trama o un punto de vista únicos, con una selección arbitraria de detalles entre infinitas posibilidades a partir de acontecimientos discretos e inconexos. Esta nueva zona que estamos viendo nacer en una colección materializada tiene como peligro la tentación de seguir acumulando aspectos multiculturales del proceso zonal por sobre la marcación de líneas evolutivas o un sistemas de correspondencias. Es más bien cómodo seguir hablando del dinamismo multicultural de la zona sin detenernos en explicar algunas de sus oscuras lógicas. En esto no nos diferenciamos tanto aún de Schlegel.

Veiravé crea una serie con aspiraciones multilingüísticas, o más bien, con referencias multiculturales abandonando voluntariamente la región, y se convierte así en un imprevisible precursor de las nuevas mutaciones. Series de referencias y de objetos 
convocados como una excursión, como una extensión de las ya extensas posibilidades de la propia lengua. Veiravé era profesor de literatura hispanoamericana y autor de unos de los manuales de la temática más importantes de la escuela secundaria argentina del siglo $\mathrm{XX}$. Entonces él puede haber comprendido que en la literatura latinoamericana no existe una unidad estilística en el espacio y tiempo sino que había que instalarla. Cuando D. H. Lawrence publica Studies in Classic American Literature en 1923 mostró cómo se formaba una tradición como preexistente. La Historia de la literatura hispanoamericana y argentina de Veiravé, de 1981, sigue en la senda que marcaba Mariátegui: la historia literaria no es cuestión de técnicas o de gustos y siempre será ejercida, subsidiaria y superficialmente, por quien carezca de una concepción filosófica e histórica.

Veiravé habla desde Chaco, una toponimia que recuerda un imperio olvidado, el qom, y un territorio nacional dentro de una selva seca -el Impenetrable-, que es la tierra del loro hablador, y es árida y venenosa. Es difícil describir una selva seca. Pero ese paisaje, como esos textos, quedará para ser analizado en otra ocasión. Menéndez Pidal usa una metáfora que parece sacada del Poema del Mio Cid al referirse a los estudios de Henríquez Ureña: "ha conquistado una nueva provincia" ${ }^{11}$. Creo que también podemos decirlo de Historia natural

\section{NOTAS}

1. Carlos Mastronardi, Formas de la realidad nacional, Obras completas, ed. de Claudia Rosa y Elisabeth Strada, Tomo II, Santa Fe, Editorial de la Universidad Nacional del Litoral, 2012, p. 712.

2. Elisa Calabrese, "Un resplandor súbito. La poesía de Alfredo Veiravé", Revista del Centro de Letras Hispanoamericanas, Año 11, $n^{\circ}$ 14, 2002, Mar del Plata, Universidad Nacional de Mar del Plata.

3. Valeria Melchiorre, “A manera de presentación”, Amelia Biagioni, Poesía completa, Adriana Hidalgo Editora, Buenos Aires, 2009, p. 6-7.

4. César Gómez, citado por Ana Belén M. Trucco Dalmas en "Santiago del Estero, 1956-1962. Dimensión, una revista de cultura y crítica" en Revista Políticas de la Memoria, n 14, 2013-2014, Buenos Aires, Cedinci.

5. Roberto Fernández Retamar menciona al colombiano Luis Carlos López, al guatemalteco Rafael Arévalo Martínez, al argentino Baldomero Fernández Moreno y al cubano José Zacarías Tallet en "Antipoesía y poesía conversacional en Hispanoamérica", Para una teoría de la literatura hispanoamericana y otras aproximaciones, La Habana, Casa de las Américas, 1975, p. 116-117.

6. Alfredo Grieco y Bavio, Cómo fueron los 60, Buenos Aires, Espasa Calpe, 1994.

7. Bruno Latour, Nunca fuimos modernos. Ensayo de antropología simétrica, trad. de Víctor Goldstein, Buenos Aires, Siglo XXI, 2007.

8. Claude Levi-Strauss, El pensamiento salvaje, México, Fondo de Cultura Económica, 2005.

9. Henri Lefevbre, La producción del espacio, Madrid, Ed. Capitán Swing, 2013.

10. Discurso pronunciado en la recepción del Premio Iberoamericano de Literatura Pablo Neruda el 14 de julio del 2004, publicado en Proceso, n. 1446, julio 18, 2004, México, p. 62-65.

11. T.S. Eliot, Sobre poesía y poetas, trad. De Marcelo Cohen, Icaria, Barcelona, 1992, p. 26.

12. Daniel Bell, Las contradicciones culturales del capitalismo, Madrid, Alianza, 2004.

13. Frederic Jameson, Teoría de la Postmodernidad, Madrid, Editorial Trotta, 2001, p. 9. 
14. Jean Baudrillard, Cultura y simulacro, Barcelona, Editorial Kairós, 2002, p 10.

15. Ver Francisco Madariaga, Tembladerales de oro (1973), Contradegüellos. Obra reunida, ed. de Roxana Páez, vol. 1, Paraná, EDUNER, 2016, p. 293-304.

16. Alfredo Veiravé, Obra Completa, ed. de María Pía Rizzotti Veiravé, vol. 2, Buenos Aires, Editorial Nuevo Hacer, 2002, p. 205.

17. Alfredo Veiravé, Escribir un poema es ensayar una magia menor y otros manuscritos inéditos, Archivo del autor.

18. Peter Sloterdijk, Esferas III. Espumas. Esferología Plural, Madrid, Ed. Siruela, 2006.

19. Ibidem, p. 79.

20. Alfredo Grieco y Bavio, "Estudios angloamericanos de un romanista. Pedro Henríquez Ureña y la literatura norteamericana", Pedro Henríquez Ureña, Ensayos, París, Colección Archivos, 1998.

21. Ramón Menéndez Pidal, "Prólogo", Pedro Henríquez Ureña, La versificación irregular en la poesía castellana, Revista de Filología Española, Madrid, Centro de Estudios Históricos, 1933.

\section{RESÚMENES}

La operatoria de Veiravé crea primero un itinerario retórico-espacial de latinoamericanización de la zona chaqueña para otorgarle luego un carácter tecnológico trasnacional. Alfredo Veiravé, en el momento de distanciamiento de la terrible influencia juaneliana, y camino a la construcción de su propia esfera poética, procura un tránsito que va de una melancólica ciudad de Gualeguay el río ausente- a una hispanoamericanización de un Chaco casi innombrado hacia 1970 y redobla la apuesta de Francisco Coco Madariaga para dejar de ser un criollo universal y ser un litoraleño interestelar.

The strategy of Veiravé creates first, a rhetorical-spatial itinerary of Latin Americanization of the Chaco area to later give it a transnational technological character. Alfredo Veiravé, at the moment of estrangement from the terrible influence of the Juanelians, and on the way to the construction of his own poetic sphere, seeks a transition from a melancholy city of Gualeguay the absent river - to a hispanoamericanization of an almost unnamed Chaco towards 1970 and doubled the bet of Francisco "Coco" Madariaga to stop being a universal criollo and be an interstellar litoraleño.

La manière d'agir de Veiravé construit, tout d'abord, un itinéraire rhétorique et spatial de l'identité latinoaméricaine de la zone du Chaco et lui octroie, ensuite, un caractère technologique transnational. Alfredo Veiravé s'éloigne de l'influence de Juan L. Ortiz en même temps que construit sa propre sphère poétique. Vairavé essaie de passer d'une ville mélancolique, comme c'est le cas de Gualeguay -le fleuve absent-, à une " hispano-américanisation » du Chaco, région qui n'a pas été nommée jusqu'aux années 1970. Alfredo Veiravé redouble le pari de Francisco Coco Madariaga, c'est-à-dire ne plus être un «criollo » universel pour devenir un « litoraleño » interstellaire. 
ÍNDICE

Palabras claves: Veiravé, paisaje, proyecto creador, objetos, implosionar Keywords: Veiravé, landscape, creator project, objects, implode Mots-clés: Veiravé, paysage, projet créateur, objets, imploser

AUTOR

CLAUDIA ROSA

Universidad Nacional de Entre Ríos / Universidad Nacional del Nordeste 